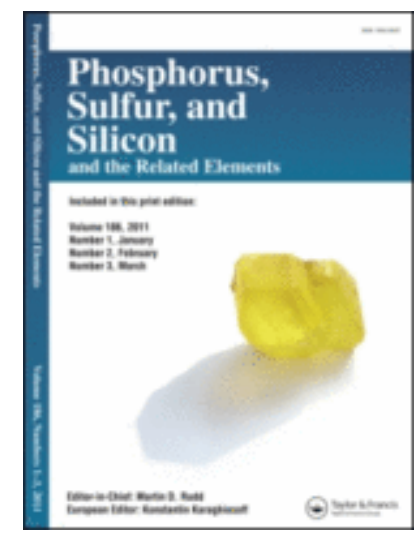

Chiral phosphorus-containing calixarenes

\begin{tabular}{|c|c|}
\hline Journal: & Phosphorus, Sulfur, and Silicon and the Related Elements \\
\hline Manuscript ID & GPSS-2018-0225.R1 \\
\hline Manuscript Type: & Original Article \\
\hline $\begin{array}{r}\text { Date Submitted by the } \\
\text { Author: }\end{array}$ & $11-$ Oct-2018 \\
\hline Complete List of Authors: & $\begin{array}{l}\text { Karpus, Andrii; Institute of organic chemistry of Natinal Academy } \\
\text { Sciences of Ukraine, Phosphoranes chemistry; Taras Shevchenko } \\
\text { National University of Kyiv, Faculty of Chemistry; Laboratoire de Chimie } \\
\text { de Coordination du CNRS, Ligands, complex architectures and catalysis } \\
\text { Yesypenko, Oleksandr; Institute of organic chemistry of Natinal Academy } \\
\text { Sciences of Ukraine, Phosphoranes chemistry } \\
\text { Cherenok, Sergiy; Institute of organic chemistry of Natinal Academy } \\
\text { Sciences of Ukraine, Phosphoranes chemistry } \\
\text { Boiko, Vyacheslav; Institute of organic chemistry of Natinal Academy } \\
\text { Sciences of Ukraine, Phosphoranes chemistry } \\
\text { Kalchenko, Olga; Institute of organic chemistry of Natinal Academy } \\
\text { Sciences of Ukraine, Phosphoranes chemistry } \\
\text { Voitenko, Zoia; Kyyivs'kij nacional'nij universytet imeni Tarasa } \\
\text { Shevchenka, Faculty of Chemistry } \\
\text { Tribrat, Oleksandr; Institute of organic chemistry of Natinal Academy } \\
\text { Sciences of Ukraine, Phosphoranes chemistry } \\
\text { Poli, Rinaldo; Laboratoire de Chimie de Coordination du CNRS, Ligands, } \\
\text { complex architectures and catalysis } \\
\text { Daran, Jean-Claude; Laboratoire de Chimie de Coordination du CNRS, } \\
\text { Ligands, complex architectures and catalysis } \\
\text { Manoury, Eric; Laboratoire de Chimie de Coordination du CNRS, Ligands, } \\
\text { complex architectures and catalysis } \\
\text { KALCHENKO, Vitaly; Institute of Organic Chemistry, National Academy of } \\
\text { Sciences of Ukraine, Phosphoranes Chemistry }\end{array}$ \\
\hline Keywords: & $\begin{array}{l}\text { calixarenes, phosphonates, phosphines, chirality, stereoselective } \\
\text { synthesis, catalysis }\end{array}$ \\
\hline
\end{tabular}




\section{SCHOLARONE ${ }^{\text {"n }}$ Manuscripts}


Phosphorus, Sulfur and Silicon, 193: xxxx-yyyy, 2018

Copyright (C) Taylor and Francis Group, LLC

ISSN: 1042-6507 print / 1563-5325 online

\title{
| Chiral phosphorus-containing calixarenes
}

\author{
Andrii Karpus ${ }^{1,2,3}$, Oleksandr Yesypenko ${ }^{*}$, Sergii Cherenok ${ }^{1}$, Vyacheslav Boiko ${ }^{1}$, Olga \\ Kalchenko ${ }^{1}$, Zoia Voitenko² ${ }^{2}$, Oleksandr Tribrat ${ }^{1}$, Rinaldo Poli ${ }^{3}$, Jean-Claude Daran ${ }^{3}$, Eric \\ Manoury $^{3}$, Vitaly Kalchenko ${ }^{1}$ \\ ${ }^{1}$ Institute of Organic Chemistry NAS of Ukraine, Kyiv, Ukraine, \\ ${ }^{2}$ Taras Shevchenko National University of Kyiv, Kyiv, Ukraine \\ ${ }^{3}$ Laboratoire de Chimie de Coordination du CNRS, Toulouse, France
}

Email:vik@ioch.kiev.ua

GRAPHICAL ABSTRACT

Abstract Phosphorus-containing inherently chiral calix[4]arenes as well as calix[4]arenes substituted with phosphinoferrocene chiral groups at the lower rim are described. Stereoselective synthesis, structure, and catalytic properties of the chiral calixarenes are discussed.

Keywords calixarenes, phosphonates, phosphines, chirality, stereoselective synthesis, catalysis.

\section{INTRODUCTION}

Calixarenes ${ }^{1,2}$ are cup-shaped macrocyclic compounds easily synthesized by one pot cyclocondensation of para-substituted phenols with formaldehyde. Calixarenes are easily amenable to chemical modification at the upper wide rim or at the lower narrow rim of the macrocycle. Due to their cup-shaped architecture calixarenes can recognize and separate similar in properties guests such as anions, cations and neutral organic molecules or biomolecules. Calixarenes modified with chiral moieties or asymmetrically substituted (inherently chiral) calixarenes discriminate of enantiomers of optically active molecules. The ability of the calixarenes to the enantiodiscrimination opens wide perspectives for their application in chiral technologies such as enantioselective sensors, shift reagents for NMR, catalysts of asymmetrical synthesis, sorbents for chromatography, nonlinear optic materials, one enantiomere drug design, etc $^{3-6}$. 
Phosphorus, Sulfur and Silicon, 193: xxxx-yyyy, 2018

Copyright (C) Taylor and Francis Group, LLC

ISSN: 1042-6507 print / 1563-5325 online

This paper is devoted to the phosphorus-contained chiral calixarenes. There are several reasons of interest to the chiral calixarenes bearing phosphorus. First of all phosphorus has rich chemistry and opens wide perspectives in design of the chiral receptors. Phosphorus is biologically friendly element and chiral organophosphorus compounds play important role in biochemistry and medicine. Chiral phosphines and phosphites are very popular ligands in metallocomplexing catalysis ${ }^{7}$.

\section{RESULTS AND DISCUSSION}

There are two families of the chiral phosphorus-contained calixarenes. The first one consists of the calixarenes functionalized with chiral substituents. The second family is so-called inherently chiral calixarenes.

It is well documented that calixarenes modified with phosphine or phosphite moieties are widely used as ligands of metallocomplexing catalysts for organic synthesis ${ }^{8}$. It is also known that metallocomplexes of chiral phosphino ferrocenes catalyze of the asymmetrical reactions ${ }^{9}$. So, it was idea to decorate the calixarene platform with a chiral phosphino pherrocene group and investigate catalytical properties of this conjugate.

As a reagent for the calixarene modification we used $S$-enatiomer of thiophosphino(methylol)ferrocene 2 possessing a planar chirality ${ }^{10}$. By the Mitsunobu reaction the chiral thiophosphinoferrocene moieties were connected to distal oxygen atoms at the lower rim of tetrahydroxycalixarene $\mathbf{1}$ and chiral bis-(thiophosphinoferrocenyl)calixarene $\mathbf{3}$ was formed. After that sulfur atoms were removed from 3 by the reaction with triamidophosphite and desirable calixarene $\mathbf{4}$ with two chiral phophinopherrocenyl groups at the lower rim was obtained with high total yield (Scheme 1, Figure 1).

The bis-(phosphinoferrocenyl)calixarene ligand $\mathbf{4}$ displayed good catalytic activity and enantioselectivity in the asymmetric Tsuji-Trost reaction. In the presence of the ligand the alkylation of 1,3-diphenylpropenyl acetate by dimethylmalonate occurs with good chemical yield and high enantiomeric excess $86 \%{ }^{10}$. 
Phosphorus, Sulfur and Silicon, 193: xxxx-yyyy, 2018

Copyright $@$ Taylor and Francis Group, LLC

ISSN: 1042-6507 print / 1563-5325 online

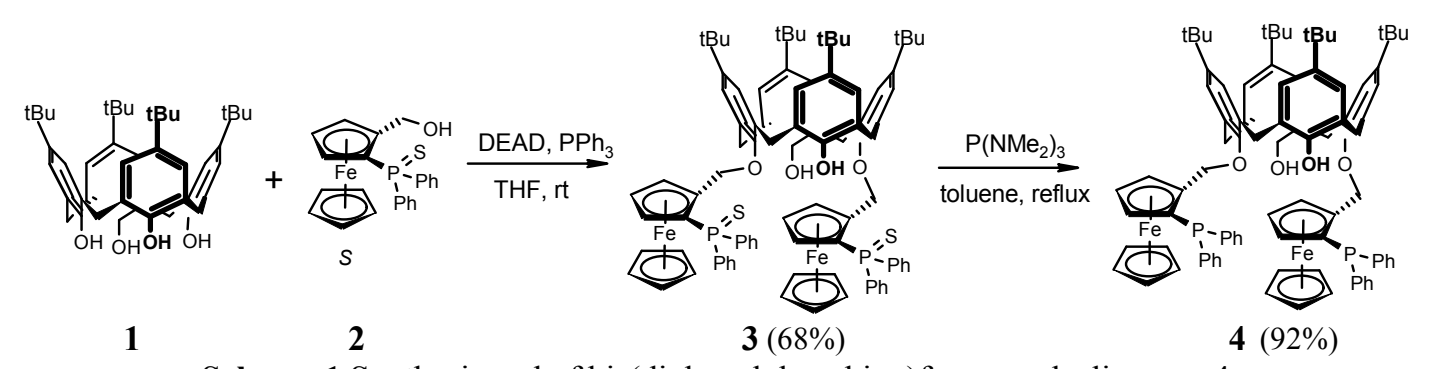

Scheme 1 Synthesis and of bis(diphenylphosphino)ferrocenylcalixarene 4

Figure $1 \mathrm{X}$-ray structure of calixarene 4

Another topic of the research is the inherently chiral calixarenes. Chirality of the compounds is induced by asymmetric disposition of any achiral substituents at the macrocyclic scaffold. The main method for synthesis of the phosphorus-containing incherently chiral calixarenes is phosphorotropic isomerisation of the symmetrical distally phosphorylated alkoxycalixarenes 5 into chiral 1,2-regioisomeres 6a,b (Scheme 2) ${ }^{11}$.

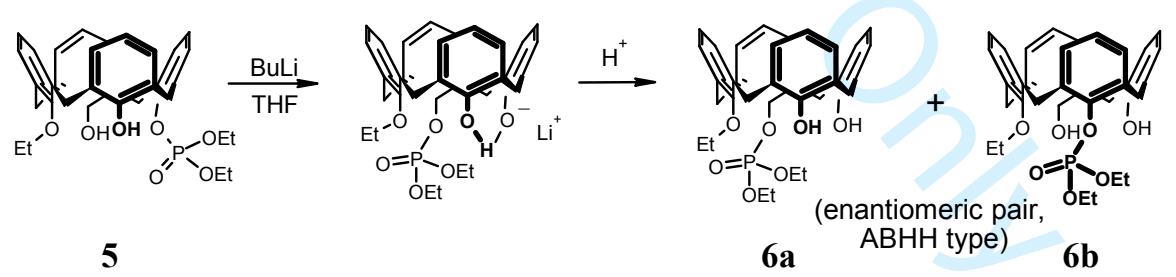

Scheme 2 Phosphorotropic isomerization of the symmetrical calixarenes 5 into chiral 1,2-regioisomeres $\mathbf{6 a}, \mathbf{b}$

It should be noted that the isomerisation is not stereoselective. Phosphorus with the same probability migrates to the both oxygen atoms and racemic mixture of two enantiomeres $6 \mathbf{a}$ and $\mathbf{6 b}$ is formed. The calixarenphosphates $\mathbf{6}$ have been converted into free acids and their diastereomeric salts with chiral L-phenylethylamine were separated by the achiral HPLC $\operatorname{method}^{11}$. 
Phosphorus, Sulfur and Silicon, 193: xxxx-yyyy, 2018

Copyright (C) Taylor and Francis Group, LLC

ISSN: 1042-6507 print / 1563-5325 online

The phosphorotropic isomerisation of the calixarene phosphate 7 bearing a chiral phenylethylamide auxiliary group in distal position is stereoselective. Phosphorus preferably migrates to one oxygen atom. Two diastereomers of the inherently chiral calixarene $\mathbf{8 a}, \mathbf{b}$ were formed in this condition with diastereomeric excess of $36 \%$ (Scheme 3$)^{12}$. The diastereomeres were separated by the column chromatography on silica-gel. Each isomer was transformed into inherently chiral calixarene phosphorus acids $\mathbf{9}$ and structure of the acids was examined by NMR and X-Ray methods.

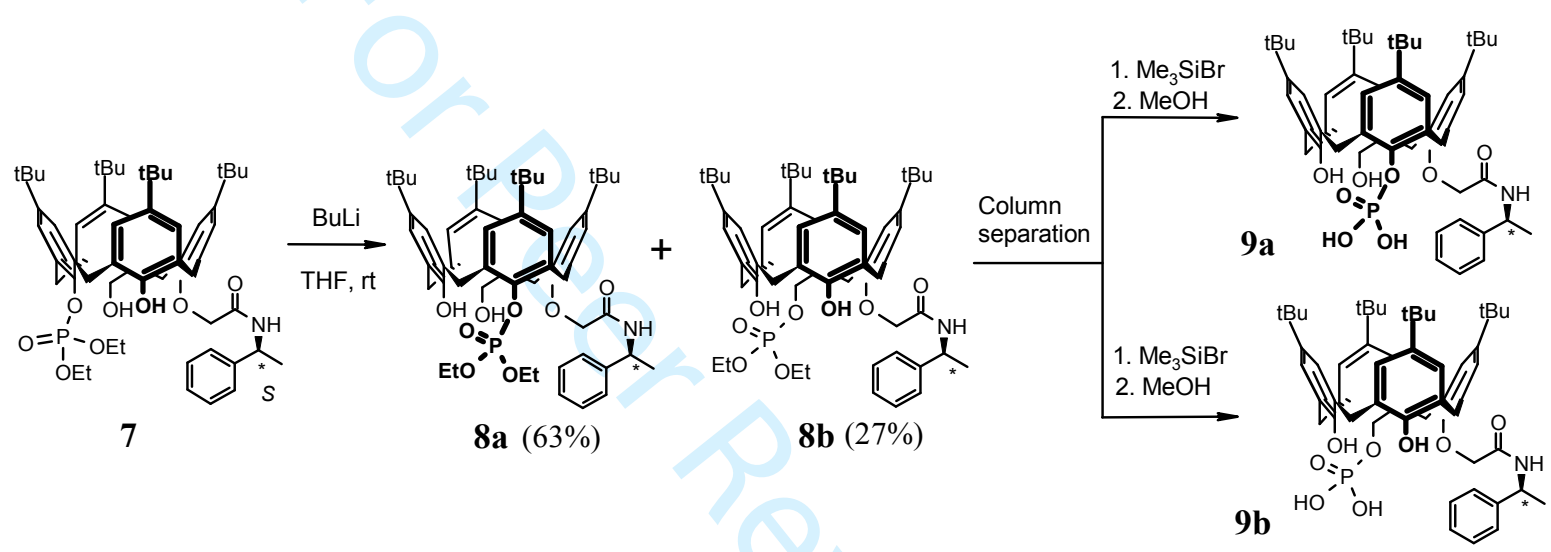

Scheme 3 Stereoselective phosphorotropic isomerization of calixarenes 7 into diastereomeres 8a,b

Optically pure calixarene phosphonous acid 16 was synthesized in accordance with Scheme $4^{13}$. As the building blocks we used optically pure chiral calixarene acetic acid $\mathbf{1 0}$ or its methyl ester $11^{14}$. The acid 10 and ester 11 have been reduced to calixarene ethanol 12 by the reaction with lithium aluminum hydride. Following the Appel reaction, alcohol 12 was transformed into calixarene ethylchloride 13a or bromine 13b. Chloride 13a was converted to calixarene ethylphosphonate $\mathbf{1 4}$ by the Arbuzov reaction with triisopropyl phosphite. However, under rigid conditions of the phosphorylation $\left(180^{\circ} \mathrm{C}\right)$ the phosphonate 14 due to intermolecular trans-esterification in accordance with the Gloede's scheme ${ }^{15}$ was transformed into spirophosphonate 15 with high yield. The spirophosphonate 15 was hydrolyzed to cyclic phosphonous acid 16 by the reaction with sodium hydroxide. The reaction is highly stereospecific. Exclusively one P-O bond was hydrolyzed and phosphonous acid $\mathbf{1 6}$ was formed in optically pure form with practically quantitative yield.

Received xx yyyy 2018; accepted xx yyyy 2018, International Conference on Phosphorus Chemistry 2018 Insert acknowledgements and thanks 
Phosphorus, Sulfur and Silicon, 193: xxxx-yyyy, 2018

Copyright (C) Taylor and Francis Group, LLC

ISSN: 1042-6507 print / 1563-5325 online

The optically pure calixarene phosphonous acid 16 catalyses the asymmetrical DielsAlder cyclisation of imines with Danishefsky diene ${ }^{13}$. Unfortunately enantiomeric excess of the reaction is low.

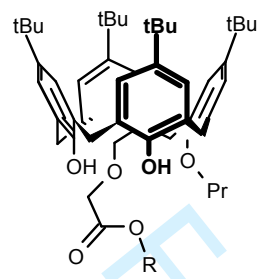

(cS)-10 $\mathrm{R}=\mathrm{H}$

$(c S)-11 \mathrm{R}=\mathrm{Me}$

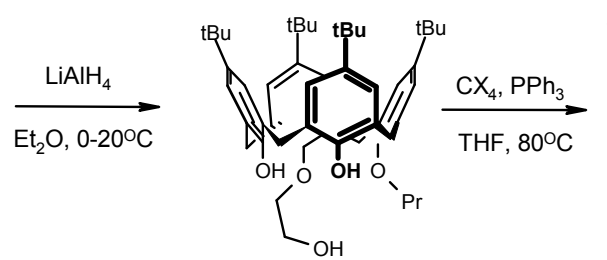

$(c S)-12(98 \%)$

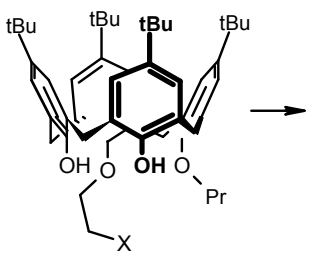

$(c S)-13 \mathbf{a} \mathrm{X}=\mathrm{Cl}(85 \%)$

$(c S)-13 b \mathrm{X}=\mathrm{Br}(88 \%)$

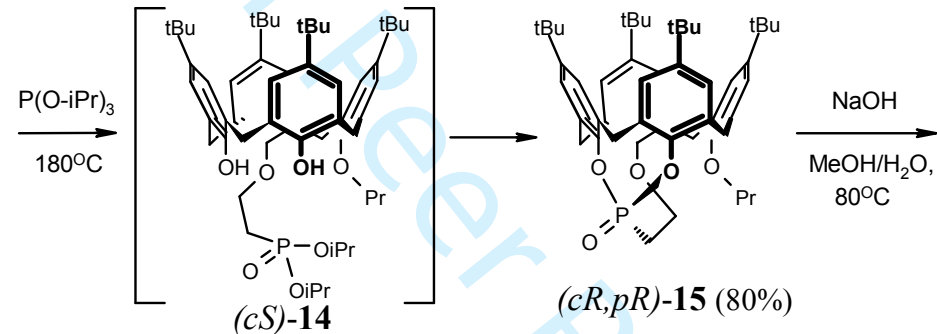

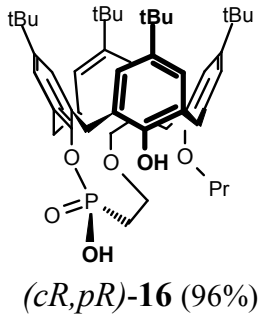

Scheme 4 Synthesis of inherently chiral calixarene phosphonous acid $\mathbf{1 6}$

The enantiomerically pure propoxydibromocalixarene $17^{16}$ possessing reactive $\mathrm{OH}$ groups at the lower rim and hydrogen or bromine atoms in para-position can be used as versatile synthon for design of phosphorylated chiral catalysts (Scheme 5) ${ }^{17}$. An attempt to exchange the proximal bromine atoms at the upper rim on phosphine oxide groups by the Nickel catalyzed Arbuzov reaction was failed, perhaps due to a sterical reason. To activate the bromine atoms the cone conformation was transformed into partial cone one by introduction two benzoyl groups into the molecule. The benzoyl derivative 18 bearing two bromine atoms at the opposite sides of the macrocycle was phosphorylated by the Nickel catalyzed Abuzov reaction with formation of diphosphine dioxide 19 in the partial cone conformation with a high yield. Hydrolytical debenzoylation of the diphosphine dioxide 19 returned the calixarene skeleton into the initial cone conformation. Reduction of the diphosphine dioxide $\mathbf{2 0}$ by phenylsilane leads to enantiomerically pure inherently chiral calixarene diphosphine 21.

In order to obtain new calixarenes phosphorylated in the upper rim, the inherently chiral dibenzoylpropoxycalixarene $\mathbf{2 2}$ in the partial cone conformation was synthesized. Regioselective bromination, nitration and formylation of 22 at the para-position of unsubstituted 
Phosphorus, Sulfur and Silicon, 193: xxxx-yyyy, 2018

Copyright (C) Taylor and Francis Group, LLC

ISSN: 1042-6507 print / 1563-5325 online

phenol ring lead to corresponding bromo 23a, nitro $23 \mathbf{b}$ and formyl 23c derivatives suitable for further phosphorylation (Scheme 6) ${ }^{18}$.

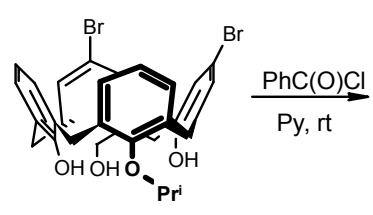

17

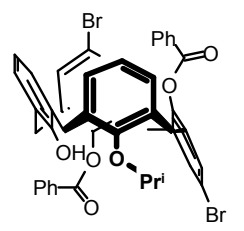

$18(62 \%)$

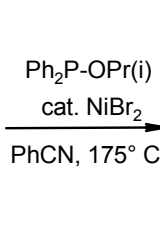

$\underset{\mathrm{PhCN}, 175^{\circ} \mathrm{C}}{\stackrel{\text { cat. } \mathrm{NiBr}_{2}}{\longrightarrow}}$

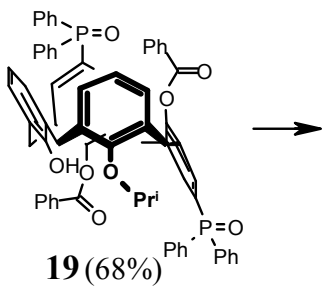

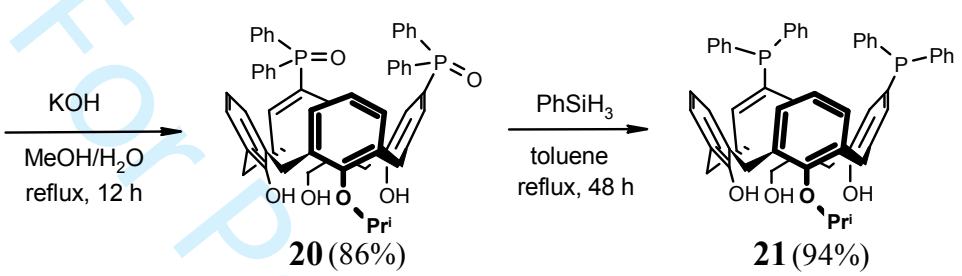

Scheme 5 Synthesis of enantiomerically pure inherently chiral calix[4]arene diphosphine $\mathbf{2 1}$

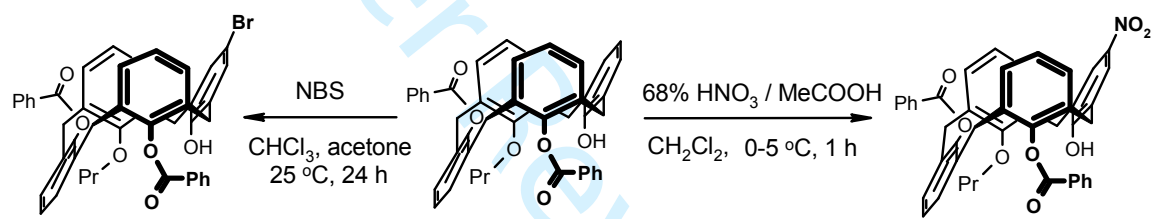

23a $(93 \%)$

22 (racemate)

$23 b(75 \%)$

\begin{tabular}{c|l}
$\mathrm{Cl}_{2} \mathrm{CHOMe}$ & $\mathrm{CH}_{2} \mathrm{Cl}_{2}$, \\
$\mathrm{TiCl}_{4}$ & $25^{\circ} \mathrm{C}, 30 \mathrm{~min}$
\end{tabular}

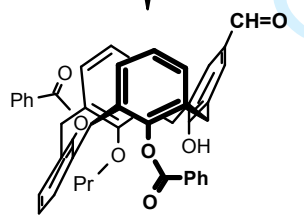

23c $(90 \%)$

Scheme 6 Synthesis of chiral building blocks 23a-c in the partial cone conformation

The benzoyl groups of calixarenes $\mathbf{2 3}$ were removed by hydrolysis with sodium hydroxide to form the upper rim functionalized ethoxycalixarenes $\mathbf{2 4}$ in the cone conformation.

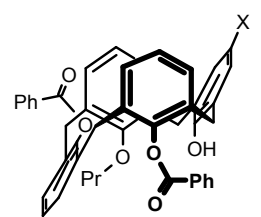

23a-c

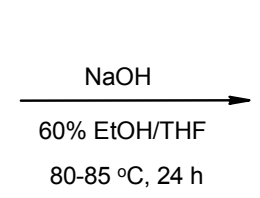

$80-85^{\circ} \mathrm{C}, 24 \mathrm{~h}$

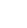

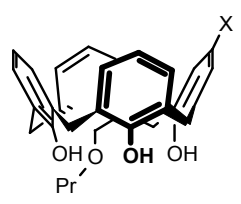

24a-c $(85-95 \%)$

Scheme 7 Synthesis of chiral building blocks 24a-c in the cone conformation

Received xx yyyy 2018; accepted xx yyyy 2018, International Conference on Phosphorus Chemistry 2018 Insert acknowledgements and thanks 
RUNNING TITLE 50 CHARACTERS OR LESS

\section{CONCLUSIONS}

Calix[4]arene modified with two chiral phosphinoferrocenyl moieties at the lower rim was synthesized by the Mitsunobu reaction of tert-butyltetrahydroxycalixarene with $S$-enatiomer of thiophosphino(methylol)ferrocene with a high yield. Convenient methods of synthesis of the inherently chiral calix[4]arenes asymmetrically substituted with achiral diphenylphosphino moieties at the upper rim as well as with phosphorus acid moieties at the lower rim were developed. The chiral phosphorus-contained calix[4]arenes are promising molecular platform for design of catalysts of asymmetrical reactions or stereochemically pure bio-active compounds as well.

\section{REFERENCES}

1. Gutsche, C. Calixarenes Revisited, The Royal Society of Chemistry: Cambridge, 1998.

2. Calixarenes 2001, Eds.: Z. Asfari, V. Boehmer, J. Harowfield, J. Vicens; Kluwer Academic Publishers: Dordrecht, 2001.

3. Boiko, V.I.; Kalchenko, V.I.; Esipenko, A.A. Chiral calixarenes, Lambert Academic Publishing: Saarbrücken, 2014.

4. Wierzbicki, M.; Jedrzejewska, H.; Szumna, A. Chiral Calixarenes and Resorcinarenes. In: Calixarenes and beyond, Neri, P.; Sessler, J.L.; Wang, M.-X., Eds.; Springer: Switzerland, 2016; pp. 13-42.

5. Guo, D.-S.; Liu, Y. Supramolecular chemistry of $p$-sulfonatocalix[n]arenes and its biological applications. Acc. Chem. Res. 2014, 47, 1925-1934.

6. Maftei, C.V.; Fodor, E.; Jones, P.G.; Franz, M.H.; Davidescu, C.M.; Neda, I. Asymmetric calixarene derivatives as potential hosts in chiral recognition processes. Pure Appl. Chem. 2015, 87, 415-439.

7. Kolodiazhnyi, O.I. Recent Developments in the Asymmetric Synthesis of P-Chiral Phosphorus Compounds. Tetrahedron-Asymmetry. 2012, 23, 1-46.

8. Sémeril, D.; Matt, D. Synthesis and catalytic relevance of P(III) and P(V)-functionalised calixarenes and resorcinarenes. Coord. Chem. Rev. 2014, 279, 58-95.

9. Gomez Arrayas, R.; Adrio, J.; Carretero, J.C. Recent applications of chiral ferrocene ligands in asymmetric catalysis. Angew. Chem. Int. Ed. 2006, 45, 7674-7715.

10. Karpus, A.; Yesypenko, O.; Boiko, V.; Poli, R.; Daran, J.-C.; Voitenko, Z.; Kalchenko, V.; Manoury, E. New Chiral Phosphinoferrocenyl Calixarenes. Eur. J. Org. Chem., 2016, 3386-3394.

11. Tairov, M.A.; Vysotsky, M.O.; Kalchenko, O.I.; Pirozhenko, V.V.; Kalchenko, V.I. Symmetrical and inherently chiral water-soluble calix[4]arenes bearing dihydroxyphosphoryl groups. J. Chem. Soc. Perkin Trans. 1, 2002, $1405-1411$. 
Phosphorus, Sulfur and Silicon, 193: xxxx-yyyy, 2018

Copyright (C) Taylor and Francis Group, LLC

ISSN: 1042-6507 print / 1563-5325 online

12. Karpus, A.O. Chiral calix[4]arenes with phosphorus-containing groups, using in asymmetric catalysis. $\mathrm{PhD}$ Dissertation, Kyiv-Toulouse, 2016.

13. Karpus, A.; Yesypenko, O.; Boiko, V.; Daran, J.-C.; Voitenko, Z.; Kalchenko, V.; Manoury, E. Synthesis of an enantiomerically pure inherently chiral calix[4]arene phosphonic acid and its evaluation as an organocatalyst. $J$. Org. Chem. 2018, 83, 1146-1153.

14. Karpus, A.O.; Yesypenko, O.A.; Andronov, L.P.; Boyko, V.I.; Voitenko, Z.V.; Chernega, A.N.; Kalchenko, V.I. Synthesis and stereochemical configuration of inherently chiral p-tert-butylcalix[4]arene carboxylic acids and their derivatives. J. Incl. Phenom. Macrocycl. Chem. 2013, 77, 175-181.

15. Gloede, J. Calixarene phosphates. Phosphorus, Sulfur, Silicon Relat. Elem. 1997, 127, 97-111.

16. Yakovenko, A.V.; Boyko, V.I.; Danylyuk, O.; Suwinska, K.; Lipkowski, J.; Kalchenko, V.I. Diastereoselective lower rim (1S)-camphorsulfonylation as the shortest way to the inherently chiral calix[4]arene. Org. Lett. 2007, 9, 1183-1185.

17. Matvieiev, Yu.; Solovyov, A.; Shishkina, S.; Shishkin, O.; Katz, A.; Boiko, V.; Kalchenko V. Upper-rim calixarene phosphines consisting of multiple lower-rim $\mathrm{OH}$ functional groups: synthesis and characterisation. Supramolecular Chem.. 2014, 26, 825-835.

18. Yesypenko, O.A.; Klyachina, M.A.; Dekhtyarenko, M.V.; Pirozhenko, V.V.; Shishkina, S.V.; Boyko, V.I.; Voitenko, Z.V.; Kalchenko, V.I. Design, synthesis and structure determination of new inherently chiral parabromoalkoxycalix[4]arenes. Supramol. Chem., 2017, 29, 49-58.

Received xx yyyy 2018; accepted xx yyyy 2018, International Conference on Phosphorus Chemistry 2018 Insert acknowledgements and thanks 


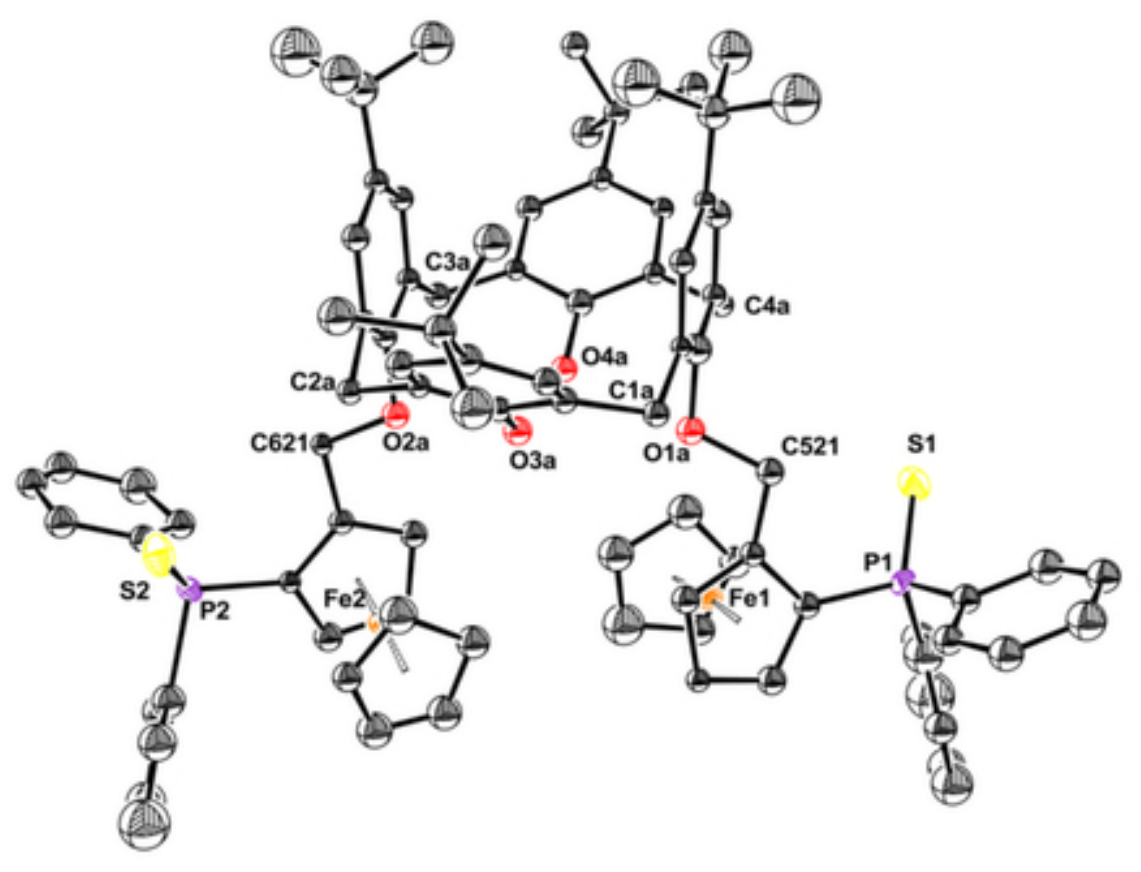

Figure $1 \mathrm{X}$-ray structure of calixarene 4 $38 \times 29 \mathrm{~mm}(300 \times 300 \mathrm{DPI})$ 


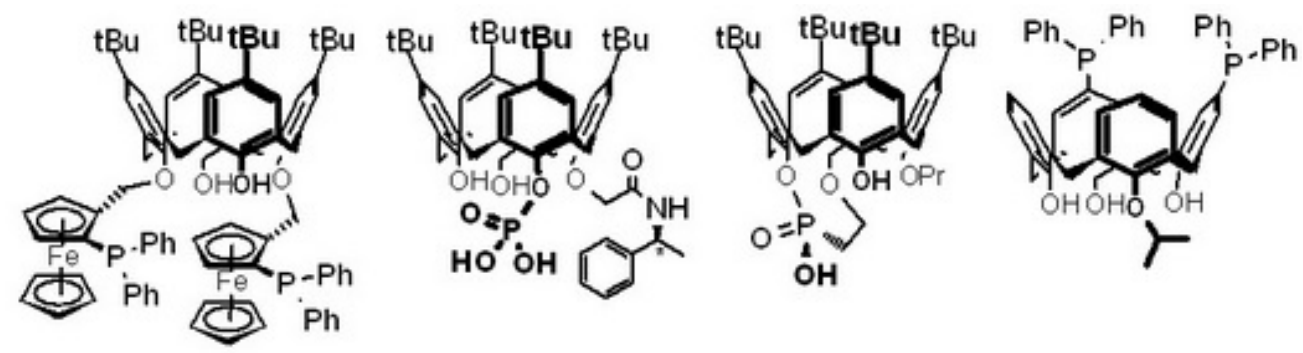

Stereoselective synthesis, structure, and catalytical properties of the chiral calixarenes are discussed

$185 \times 65 \mathrm{~mm}(72 \times 72 \mathrm{DPI})$ 